\title{
Early administration of oral morphine to orthopedic patients after surgery
}

\author{
Ruth Zaslansky, DSc \\ Elon Eisenberg, MD \\ Bezalel Peskin, MD \\ Elliot Sprecher, $\mathrm{PhD}$ \\ Daniel N. Reis, MD \\ Chaim Zinman, MD \\ Silviu Brill, MD
}

\section{ABSTRACT}

Current pain treatment guidelines advise against providing analgesics for postoperative pain using intramuscular injections, as this generally provides poor pain relief. However, this route remains the most prevalent treatment method. Intravenous or epidural patient-controlled-analgesia methods reduce pain effectively but are expensive, labor intensive, and available to only a limited number of patients. We propose administering the analgesics using oral analgesics and have developed a simple protocol for treating postoperative pain by use of oral morphine. After a variety of orthopedic surgeries, patients were given "around-the-clock," oral, immediate-release morphine. Efficacy of the treatment (pain scores and adverse effects) was assessed $24 \pm 2$ hours after surgery. Data were collected prospectively from 95 patients, who received an average of $61 \pm 30$ (SD) $\mathrm{mg}$ morphine. Average pain scores were 2.4/10 ( \pm 1.4$)$ at rest and 4.0/10 $( \pm 1.4)$ during movement in bed. Nausea and vomiting, the most common adverse effects, were reported by 22 (23 percent) patients. Naloxone was not administered to any of the patients. Oral morphine given in the early postoperative time to patients after a variety of orthopedic surgeries was effective and safe.

Key words: postoperative pain, oral analgesics, oral morphine, orthopedic surgery

\section{INTRODUCTION}

Pain after orthopedic surgery can be severe. ${ }^{1}$ In one study, 40 percent of orthopedic patients reported severe pain during the first 24 hours after surgery. ${ }^{2}$ It is widely accepted that effective analgesia for postoperative pain is a component of good care, ${ }^{3}$ as pain relief is a "universal human right." ${ }^{4}$ It is also known that alleviation of pain facilitates early ambulation and may thus be important in reducing the incidence of postoperative complications. ${ }^{5}$ Indeed, prevention and treatment of pain in its acute phase may even prevent the progression to chronic pain. ${ }^{6}$

Management of pain remains a complex issue in healthcare despite the proliferation of drugs and treatment techniques. ${ }^{7}$ Surveys continue to indicate that it is still undertreated. ${ }^{8}$ In a review of 21 studies published over the last 40 years, there is no change in the 30 to 70 percent of patients reporting moderate to severe levels of pain after surgery. ${ }^{9}$ One possible explanation for this may be the widespread practice of providing analgesics by intramuscular administration, on a "patient-demand" basis. ${ }^{10}$ This route continues to be the most prevalent method for providing analgesics postoperatively, despite contrary recommendations from current treatment guidelines. ${ }^{5,11}$

Intravenous or epidural patient-controlled analgesia or physician-controlled epidural treatment provides "stateof-the-art" analgesia but is available to only a limited number of postoperative patients (10 to 25 percent), even in major university hospitals. ${ }^{12}$ The limited availability is due to such reasons as the high cost of labor and materials, need for intensive and complex monitoring, ${ }^{12}$ and the need for major reorganization of medical and nursing services before these techniques can be widely implemented.

A majority of postoperative patients can achieve adequate analgesia simply, safely, and effectively without the need for expensive and sophisticated methods. However, achieving this goal requires finding hospital-wide solutions to problems such as systematic assessment of pain, provision of analgesics "around-the-clock," titration of 
analgesics to individual requirements, and combination of opioid and nonopioid medications. ${ }^{5,11,12}$ These principles were applied in a number of studies using intramuscular injections to provide the analgesics. ${ }^{12,13}$

Scores of $\leq 3 / 10$ represent pain that is "mild" and can be regarded as the "zone of analgesic success." 14 We therefore aimed at obtaining such scores for rest- and movement-related pain in orthopedic surgical patients by following the currently recommended pain management practices while providing morphine by the oral rather than the intramuscular route.

In this report, we assess the efficacy of providing morphine by the oral route in the early postoperative timeframe by assessing two clinical outcomes: pain relief and frequency of morphine-related adverse effects.

\section{METHODS}

\section{Participants and procedure}

This was an open, observational, prospective survey conducted in the Orthopedics Department at the Rambam University Medical Center in Israel. Data were collected between August 1999 and March 2000. Institutional Review Board approval was obtained prior to initiating treatment and collecting data. Administration of oral morphine postoperatively was the standard method of treating postoperative pain in the department of orthopedics where the survey took place. We present results obtained from patients for which full documentation was available in their medical record regarding the dosage of morphine in the first 24 hours after surgery, pain at rest and movement, and adverse effects.

\section{Postoperative analgesic medication}

Patients were prescribed immediate-release morphine tablets (Morphine Immediate Release [MIR]; Rafa Laboratories, Israel). Onset of action of MIR is 20 to 30 minutes, and duration of action is four to five hours. With MIR, peak blood plasma concentration occurs at 1.1 hours; it has a half-life of two to three hours and bioavailability of 20 to 40 percent (per manufacturer's datasheet). Dosing was based on patient age rather than on weight. ${ }^{15}$ We used the recommended parenteral dose to treat postoperative pain and converted it to the oral dose based on an equianalgesic ratio of $1: 3,5,11,15$ The recommended dose for patients up to the age of 65 years was 15 or 30 mg, six times daily, and for patients over 65 years, 7.5 or $15 \mathrm{mg}$, six times daily. A "rescue dose" of 7.5 or $15 \mathrm{mg}$ morphine was available for patients for whom pain relief was insufficient. The specific dose prescribed to each patient was determined by the attending surgeon. Morphine tablets were made available to patients immediately upon their return from the post-anesthesia recovery room, where they typically had remained for one to two hours after surgery. At night, patients were not awakened from sleep to administer the medication, but it was made available if required. This regimen was followed until reported pain levels were sufficiently low to switch over to nonopioid medication, typically 24 to 72 hours after surgery.

\section{Patient assessments}

Intensity of patient pain was assessed during the first $24 \pm 2$ hours after surgery. The pain was estimated by the patient with one of three nurses participating in the survey by means of a numerical pain scale $(0=$ "no pain" to $10=$ "unbearable pain"). Patients were asked to grade current pain at rest, while lying still in bed, and also when moving the surgically treated limb (movement-related). Assessments were made independently of when the medication was administered. The rationale for this evaluation procedure was that the objective of the treatment regimen was to achieve pain scores $\leq 3 / 10$ for both rest and movement throughout the day rather than at a specific time after administration of the analgesic.

We also assessed 1) the incidence of adverse effects related to morphine: nausea and vomiting, dizziness, sedation, confusion, cessation of treatment due to adverse effects, and respiratory depression necessitating treatment by naloxone; 2) the dose of oral morphine administrated; and 3) the type of surgery and type of anesthesia.

Type of surgery was determined by two of the authors (BP and DNR), who classified all surgical procedures of patients in the study into five categories (Table 1), based on the type of tissue involved in the surgery (bone or soft), type of surgery (emergency or elective), and extent of surgery (minor or major). Data were pooled by type of surgery, and an analysis of variance was performed to determine the overall effectiveness of the oral treatment with respect to the different types of surgeries. Additionally, the Tukey-Kramer HSD test was applied to reveal variant results based on surgery type.

The Student t-test was performed to determine whether type of anesthesia (general vs. regional) had an effect on postoperative pain scores.

JMP version 4.01 (SAS Institute, Cary, NC) and Excel for Windows NT (Microsoft Corp, Redmond, WA) were used for the statistical analysis. A value of $p<.05$ was regarded as statistically significant.

\section{RESULTS}

Data were obtained from 95 patients (59 women and 36 men; age range, 19 to 93 years; average \pm SD age, 58.8 \pm 21 years). 
Table 1. Types of surgical procedures and number of patients in each category, dosage of oral morphine and pain scores for each surgical category

\begin{tabular}{|c|c|c|c|c|c|c|}
\hline Category & Surgical procedure & $\begin{array}{c}\text { Number of } \\
\text { patients }\end{array}$ & $\begin{array}{c}\text { Average } \\
\text { morphine }(\mathrm{mg}) / \\
24 \text { hours }( \pm \mathrm{SD})\end{array}$ & $\begin{array}{l}\text { Range } \\
\text { (mg) }\end{array}$ & $\begin{array}{c}\text { Pain at rest } \\
\text { average }( \pm S D)\end{array}$ & $\begin{array}{c}\text { Movement- } \\
\text { related pain } \\
\text { average }( \pm S D)\end{array}$ \\
\hline 1 & Neck of femur fractures & 11 & $46( \pm 28.0)$ & $15-90$ & $3( \pm 1)$ & $4.8( \pm 1.4)$ \\
\hline 2 & $\begin{array}{l}\text { Other fractures (open or } \\
\text { closed treatments) }\end{array}$ & 22 & $70( \pm 27)$ & $30-105$ & $3.0( \pm 1.7)$ & $4.0( \pm 1.7)$ \\
\hline 3 & $\begin{array}{l}\text { Major elective surgery, } \\
\text { e.g., total hip or total } \\
\text { knee replacement }\end{array}$ & 38 & $60( \pm 30)$ & $15-120$ & $2.2( \pm 1.1)$ & $3.9( \pm 1.1)$ \\
\hline 4 & $\begin{array}{l}\text { Other lesser elective } \\
\text { procedures }\end{array}$ & 8 & $71( \pm 32)$ & $30-120$ & $1.9( \pm 1.5)$ & $2.4( \pm 1.2)$ \\
\hline 5 & $\begin{array}{l}\text { Soft tissue surgery } \\
\text { with minimal bone } \\
\text { involvement }\end{array}$ & 16 & $58( \pm 28)$ & $15-90$ & $2.9( \pm 1.6)$ & $4.4( \pm 1.5)$ \\
\hline & Total & 95 & $61( \pm 30)$ & $15-120$ & $2.4( \pm 1.4)$ & $4.0( \pm 1.4)$ \\
\hline
\end{tabular}

\section{Pain scores}

The average pain score at rest was $2.4 \pm 1.4$. Average movement-related pain was $4.0( \pm \mathrm{SD} 1.4)$ The breakdown of average pain scores according to type of surgery are listed in Table 1.

\section{Adverse effects}

Adverse effects and their prevalence are listed in Table 2.

\section{Dosage of oral morphine}

Doses of oral morphine administered during the first 24 hours after surgery are shown in Table 1 . The data are grouped by type of surgery. No significant difference in consumption of oral morphine was found between the $\operatorname{groups}(\mathrm{p}=0.21)$.

\section{Effect of surgical parameters on pain scores}

Type of surgery. When types of surgery were compared to pain scores at rest and during movement, a trend was found for both rest $(\mathrm{p}=0.056)$ and movementrelated pain $(\mathrm{p}=0.057)$. Further inspection of the data suggested that one patient, at rest, had an unusually high pain score, and his data were eliminated. This did not change the statistical trend $(\mathrm{p}=0.075)$. The trend is probably due to patients in group four ("Other lesser elective procedures") and, to a lesser extent, group three ("Major elective surgery, e.g., total hip or total knee replacement"), having slightly lower pain scores (Table 1).

Our findings indicate that on the whole, type of surgery is not tightly associated with postoperative pain of these orthopedic patients.

\section{Type of anesthesia}

Of the 95 patients, 42 (44 percent) were operated on under general anesthesia, 51 (54 percent) received regional anesthesia, and two patients received combined anesthesia. The latter two patients were excluded from the analysis. Pain scores were not associated with the type of anesthesia (pain score: rest, not significant $[\mathrm{p}=$ $0.4]$; movement-related, not significant $[p=0.44]$ ).

\section{DISCUSSION}

The main finding of this survey is that morphine administered orally during the first 24 hours after surgery to patients having undergone a variety of orthopedic surgical procedures enabled most to have mild pain at rest. Movement-related pain, while not reduced to such low levels, came fairly close. Furthermore, the treatment regimen was safe. The medication was effective equally in patients after general anesthesia or regional anesthesia.

The motivation for this study was the high incidence of poor postoperative pain relief among patients in our 


\begin{tabular}{|l|c|}
\hline \multicolumn{2}{|c|}{$\begin{array}{c}\text { Table 2. Incidence of adverse effects } \\
\text { in patients (n = 95) receiving oral morphine }\end{array}$} \\
\hline \multicolumn{1}{|c|}{ Adverse effect } & $\begin{array}{c}\text { Frequency } \\
\text { n (percent) }\end{array}$ \\
\hline None & $62(63.5)$ \\
\hline Nausea and vomiting & $22(23)$ \\
\hline Dizziness & $4(4.2)$ \\
\hline Confusion & $7(7.3)$ \\
\hline Sedation & $3(3.1)$ \\
\hline $\begin{array}{l}\text { Cessation of treatment due to } \\
\text { adverse effects }\end{array}$ & $6(6.25)$ \\
\hline Use of naloxone & $0(0)$ \\
\hline
\end{tabular}

hospital. It is impractical and unnecessary to provide treatment with intravenous or epidural patient-controlled analgesia to many postoperative patients. Oral administration of analgesics is the mainstay treatment for chronic and cancer pain, due to ease of titration, relatively steady blood levels obtained, convenience to patients and staff, and low costs in both labor and equipment associated with their administration.

Oral administration is generally regarded as unsuitable during the early postoperative period due to such reasons as postoperative ileus leading to decreased gastrointestinal motility and, therefore, poor drug absorption, and nausea and vomiting that may also limit patients from oral intake. ${ }^{16}$ Consequently, it is common practice to provide oral analgesics only after detecting gastric motility indicating a return of gastrointestinal functioning. ${ }^{17,18}$ As orthopedic surgery does not involve open intra-abdominal procedures, ileus in the small bowel where morphine is absorbed, is transient, ${ }^{17}$ or is not manifest. ${ }^{18}$ Therefore, after this type of surgery, opioids can be absorbed early on in the postoperative period. Nausea and vomiting can be treated with antiemetics. ${ }^{19}$ Many patients post-nonabdominal surgery can tolerate sips of fluid in the early period following surgery. If "patients can have soup for supper and are taking other medications orally, there is little reason to give their analgesics parenterally." ${ }^{20}$

We chose immediate-release morphine tablets for the following reasons: morphine is the "gold standard" for treatment of severe pain. The immediate-release form provides fairly rapid analgesia, as onset of action is 20 to 30 minutes following administration. This is similar to onset after intramuscular administration. Provision of the medication "around-the-clock," with additional doses when the pain is not sufficiently reduced, enables easy titration. These are essential features of a 24- to 72-hour routine to be used for the treatment of acute pain. ${ }^{21}$

A number of studies have described use of oral analgesia in the early postoperative period in orthopedic patients, once patients are awake from surgery and are able to drink: $20 \mathrm{mg}$ of liquid morphine, every four hours $^{21} ; 15 \mathrm{mg}$ of liquid morphine, on a patient-controlled basis ${ }^{22}$; and $20 \mathrm{mg}$ sustained release morphine, twice daily. ${ }^{13}$ The principal finding of each of these studies is that oral morphine given at this early postoperative stage provides effective analgesia, and that medication given around the clock was more effective than when provided on a patient-demand basis. Adverse effects were similar in both oral and control groups. ${ }^{13,21}$

The principal differences between those previous studies and the current one relate to their relatively small number $(n=39, n=23, n=20)^{13,21,22}$ of patients. Additionally, in the other studies, all patients received regional anesthesia. In this survey, patients divided almost equally between those who received regional and general anesthesia. We found that even the latter patients were able to ingest oral medication a few hours after surgery.

Nausea and vomiting composed the principal adverse event patients experienced in this survey. Our finding of an incidence of 23 percent is well within the expected range when morphine is provided by other routes. Nausea and vomiting were reported by up to 30 percent of patients receiving intrathecal and epidural opioids $^{23}$ and by up to 64 percent of patients receiving morphine by intramuscular injection. ${ }^{24}$ Up to 25 percent of patients experience nausea and vomiting within the first 24 hours after surgery, and this may be even as high as 70 to 80 percent in high-risk patients, in response to the anesthesia. ${ }^{19}$

The most feared adverse event connected to use of opioids is respiratory depression. None of the patients we followed required treatment with naloxone. Clearly, a much larger sample of patients is necessary to provide a more clinically significant picture regarding the frequency of adverse events in response to oral morphine. $^{25}$

\section{CONCLUSIONS}

Our findings support a number of previous studies, demonstrating that oral morphine administered in the early postoperative period appears to be simple, effective, and safe in a variety of orthopedic surgical procedures.

\section{ACKNOWLEDGMENTS}

We thank Dalia Zucker, RN, Jaqueline Cohen, RN, Ilana Kahn, RN, and Larissa Hoz, RN, for their assistance in data collection. 
Ruth Zaslansky, DSc, Unit for Quality Improvement, Rambam Medical Center, Faculty of Medicine, TechnionIsrael Institute of Technology, Haifa, Israel; current address: Department of Anaesthesia, Charité-Universitätsmedizin Berlin, Campus Benjamin Franklin, Berlin, Germany. Elon Eisenberg, MD, Pain Relief Unit, Rambam Medical Center, Faculty of Medicine, Technion-Israel Institute of Technology, Haifa, Israel.

Bezalel Peskin, MD, Department of Orthopedics and Traumatology B, Rambam Medical Center, Faculty of Medicine, Technion-Israel Institute of Technology, Haifa, Israel.

Elliot Sprecher, PhD, Department of Neurology, Rambam Medical Center, Faculty of Medicine, Technion-Israel Institute of Technology, Haifa, Israel.

Daniel N. Reis, MD, Department of Orthopedics and Traumatology B, Rambam Medical Center, Faculty of Medicine, Technion-Israel Institute of Technology, Haifa, Israel.

Chaim Zinman, MD, Department of Orthopedics and Traumatology B, Rambam Medical Center, Faculty of Medicine, Technion-Israel Institute of Technology, Haifa, Israel.

Silviu Brill, MD, Pain Relief Unit, Department of Anesthesia and Intensive Care, Sheba Medical Center, Israel.

\section{REFERENCES}

1. Fanciullo GJ, Ferrante FM: Analgesia after orthopedic surgery. In Ferrante FM, VadeBoncouer TR (eds): Postoperative Pain Management. New York: Churchill-Livingstone, 1993, pp 531-548.

2. Zaslansky R, Eisenberg E, Peskin B, et al.: Can morphine administered orally in the immediate postsurgical period make orthopedic patients "pain free"? J Pharm Care Pain Sympt Control. 2000; 8: 21-41.

3. Joint Commission on Accreditation of Healthcare Organizations: Pain management standards. Effective January 1, 2000. Available at www.jacho.org/standard/pain_hap.html. Accessed September 2005.

4. Cousins MJ, Brennan F, Carr DB: Pain relief: A universal human right. Pain. 2004; 112(1-2): 1-4.

5. Carr DB, Jacox AK, Chapman CR, et al.: Acute Pain Management Guideline Panel: Acute Pain Management: Operative or Medical Procedures and Trauma. Clinical Practice Guideline No. 1. AHCPR Pub. 92-0032. Rockville, MD: Agency for Health Care Policy and Research, Public Health Service, US Department of Health and Human Services, 1992, 20-21.

6. Carr DB, Goudas LC: Acute pain. Lancet. 1999; 1: 2051-2058.

7. Rowlingson JC: Postoperative pain: To diversity is to satisfy. Anesth Analg. 2005; 101: S1-S4.
8. Carr DB, Reines HD, Schaffer J, et al.: The impact of technology on the analgesic gap and quality of acute pain management. Reg Anesth Pain Med. 2005; 303: 286-291.

9. Berry PH, Chapman CR, Covington ED, et al.: Pain: Current understanding of assessment, management, and treatments. Natl Pharm Council. 2001; 13-17: 75-78.

10. Grass JA: Patient-controlled analgesia. Anesth Analg. 2005: 101 (Suppl): S44-S56.

11. American Pain Society: Principles of Analgesic Use in the Treatment of Acute Pain and Cancer Pain. Oakbrook, IL: APS, 1999.

12. Rawal N: Organization of acute pain services: A low cost model. Pain. 1994; 57: 117-123.

13. Bourke M, Hayes A, Doyle M, et al.: A comparison of regularly administered sustained release oral morphine with intramuscular morphine for control of postoperative pain. Anesth Analg. 2000; 90: 427-430.

14. Mantha S, Thisted R, Foss J, et al.: A proposal to use confidence intervals for visual analogue scale data for pain measurement to determine clinical significance. Anesth Analg. 1993; 77: 1041-1047.

15. Macintyre PE, Jarvis DA: Age is the best predictor of postoperative morphine requirements. Pain. 1995; 64: 357-364.

16. Rawal N: Management of Acute and Chronic Pain. London: BMJ Books, 1998, p 64.

17. Rogers MC, Tinker JH, Covino BG, et al.: Principles and Practice of Anesthesiology. St Louis: Mosby-Year Book, 1978, p 122.

18. Schwartz SI: Principles of Surgery. New York: McGraw-Hill, 1999, pp 467-477.

19. Gan TJ, Meyer T, Apfel CC: Consensus Guidelines for Managing Postoperative Nausea and Vomiting. Anesth Analg. 2003; 97: 62-71.

20. Moote CA: The prevention of postoperative pain. Can J Anesth. 1994; 41: 527-533.

21. McCormack JP, Warriner CB, Levien MG, et al.: A comparison of regularly dosed oral morphine and on-demand intramuscular morphine in the treatment of postsurgical pain. Can J Anesth. 1993; 40: 819-824.

22. Striebel HW, Scheitsa W, Philippi W, et al.: Quantifying oral analgesic consumption using a novel method and comparison with patient-controlled intravenous analgesic consumption. Anesth Analg. 1998; 86: 1051-1053.

23. Chaney MA: Side effects of intrathecal and epidural opioids. Can J Anaesth. 1995; 42: 891-903.

24. Choiniere M, Rittenhouse B, Perreault S, et al.: Efficacy and costs of patient-controlled analgesia versus regularly administered intramuscular opioid therapy. Anesthesiology. 1998; 89: 1377-1388.

25. Moore RA, Gavaghan D, Tramer MR, et al.: Size is everything: Large amounts of information are needed to overcome random effects in estimating direction and magnitude of treatment effects. Pain. 1998; 783: 209-216. 